\title{
Hepatitis $B$ and $C$ virus reactivations under biologic treatments in patients with rheumatic diseases: long-term results from a single-center
}

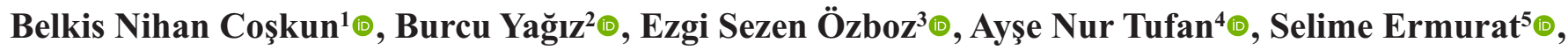

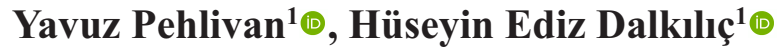

${ }^{1}$ Department of Internal Medicine, Division of Rheumatology, Uludağ University School of Medicine, Bursa, Turkey

${ }^{2}$ Department of Rheumatology, Afyonkarahisar State Hospital, Afyonkarahisar, Turkey

${ }^{3}$ Department of Internal Medicine, Bornova Türkan Özilhan State Hospital, İmir, Turkey

${ }^{4}$ Department of Rheumatology, Haseki Training and Research Hospital, İstanbul, Turkey

${ }^{5}$ Department of Rheumatology, University of Health Sciences, Bursa Yüksek Ihtisas Training and Research Hospital, Bursa, Turkey

\begin{abstract}
Objectives: To find out the effects and prevalence of disease-modifying antirheumatic drugs (DMARDs) and anti-TNF agents on hepatitis B virus (HBV) reactivation in hepatitis B surface antigen (HBsAg)-positive patients with rheumatic diseases (RD).

Methods: This retrospective study was conducted on 1,548 RD patients. Patients' medical records regarding immunological profiles, clinical courses, and outcomes, were obtained. In this research, the patient used conventional DMARDs (cDMARDs) and biological DMARDs (bDMARDs). A drug exposure was considered when a patient was administered GC, cDMARDs, or bDMARDs for $>4$ weeks. Serum alanine aminotransferase (ALT), aspartate aminotransferase (AST), and bilirubin were measured. HBsAg, HBV DNA assay, anti-HCV and HIV were identified.

Results: HBsAg was positive in $19(37.3 \%)$ patients. Anti-HBs in $5(9.8 \%)$ patients and anti-HBc IgG in 35 $(68.6 \%)$ patients were positive. All patients with HBsAg positivity were receiving antiviral prophylaxis. Anti$\mathrm{HCV}$ was positive in $25.5 \%(\mathrm{n}=13)$ of individuals . There was not any reactivation among the patients. No HBV reactivation was observed.

Conclusions: Screening before treatment and give prophylaxis to patients who have occult hepatitis or hepatitis $\mathrm{B}$, may be an important factor in the absence of reactivation. Hepatitis screening should be performed in all patients prior to biological treatment is initiated.
\end{abstract}

Keywords: Hepatitis, rheumatic disease, reactivation, biologic treatment. Disease-modifying antirheumatic drugs, occult Hepatitis.

$\mathrm{T}$ he primary cause of chronic hepatitis, end-stage liver disease, and hepatocellular carcinoma (HCC) is hepatitis B virus (HBV) infection [1-3]. Around 350 million people worldwide are afflicted with $\mathrm{HBV}$, which causes between 0.5 and 1 million fa- talities each year [4]. Similarly, hepatitis C virus (HCV) infects around 170 million people [5].

HBV infection is a significant issue for rheumatologists, as reactivation of HBV can occur as a side effect of immunosuppressive medications (ISDs) [6]. 
Numerous conventional disease-modifying antirheumatic medications (cDMARDs), such as glucocorticoids, methotrexate (MTX), hydroxychloroquine, sulfasalazine, and leflunomide, as well as biological DMARDs, such as etanercept, adalimumab, golimumab, infliximab, certolizumab, tocilizumab, TNFalfa is significant because it inhibits HBV replication and is capable of eradicating the virus [7]. Notably, rituximab, a B cell depleting drug, is frequently used to treat rheumatic disorders. However, prolonged use of potentially hepatotoxic DMARDs, such as MTX, is likely to result in HBV reactivation, and a link between anti-TNF therapy and HBV activation has been established $[8,9]$.

The American Gastroenterological Association (AGA) Institute emphasized the possibility of $\mathrm{HBVr}$ infection associated with chemotherapeutic treatments and immunosuppressive medicines in 2015 [10-11]. As a result, immunocompromised patients should be evaluated for HBV and HCV infection [12]. The prophylactic antiviral medication is extremely useful since it prevents $\mathrm{HBV}$ reactivation in $\mathrm{HBsAg}$-positive patients receiving anti-TNF or DMARD therapy [7]. The purpose of this study is to determine the effect and prevalence of DMARDs and anti-TNF medications on $\mathrm{HBV}$ and $\mathrm{HCV}$ reactivation in patients with rheumatic illnesses who are HBsAg positive.

\section{METHODS}

\section{Patients}

Between January 2006 and December 2012, we retrospectively analyzed 1,548 individuals with $\mathrm{RD}$ who had available HBsAg and HCV data at a university hospital. Without taking anti-HBV prophylaxis, 19 patients tested positive for HBsAg at the time of diagnosis or prior to immunosuppressive treatment. We received medical documents pertaining to immunological profiles, clinical courses, and results.

The inclusion criteria for our patients to participate in the present research were (i) patients with RD (rheumatoid arthritis [RA], ankylosing spondylitis [AS], psoriatic arthritis [PsA], spondyloarthropathy [SpA], vasculitis, systemic lupus erythematosus, behcet disease, and systemic sclerosis); (ii) the intervention consisted of anti-TNF agents, Rituximab, Tocilizumab, Abatacept, Ustekinumab, Tofacitinib,
Cyclophosphamide, and DMARDs; (iii) sufficient data on patience regarding the effects of anti-TNF agents or DMARD on HBV reactivation.

\section{Immunosuppressive Therapy}

Methotrexate, hydroxychloroquine, and sulfasalazine were used as cDMARDs in this study. AntiTNF medicines, rituximab (anti-CD20 monoclonal antibody), tocilizumab (anti-interleukin 6 receptor monoclonal antibody), and abatacept (cytotoxic $\mathrm{T}$ lymphocyte-associated antigen 4 immunoglobulin) were listed among the bDMARDs. When a patient got GC, cDMARDs, or bDMARDs for a period of more than 4 weeks, exposure to medicines was assessed.

\section{Serological Tests of Viral Hepatitis Markers}

We determined serum alanine aminotransferase (ALT), aspartate aminotransferase (AST), and bilirubin using a 24-factor automated chemical analyzer and standard reagents. The Architect-plus 2001 chemiluminisans method was used to determine the hepatitis B surface antigen. Plasma samples from patients were purified using the automated m2000sp (Abbott Molecular, USA) instrument for DNA extraction. The acquired DNA was amplified using the Real-Time PCR on a m2000rt (Abbott Molecular, USA) equipment using an Abbott Real-Time HBV kit.

The study protocol was approved by the Local Clinical Research Ethics Committee (decision number: 2021-6/43).

\section{Statistical Analysis}

Statistical analysis was performed with the SPSS program, version 23 . The demographic data of the patients were presented as frequency and percentage for qualitative variables and mean and standard deviation for qualitative variables. For all tests, probability values (values) of $<0.05$ were considered to indicate statistical significance.

\section{RESULTS}

The mean age of the 51 patients was $50.9 \pm 13.51$ years (range: $20-69$ years). Out of 51 patients, 58.8\% of them were females and $41.2 \%$ of them were males (see Appendix 1 for patient characteristics).

HBsAg positivity was observed in $37.3 \%$ of pa- 
tients $(\mathrm{n}=19)$, Anti-HBs positivity was observed in $9.8 \%$ of patients $(\mathrm{n}=5)$, and Anti-HBc IgG positivity was observed in $68.6 \%$ of patients $(n=35)$. It is worth noting that data for Anti-HBc IgG were absent. There were no patients who tested positive for Anti-HBc IgM. All patients with HBsAg positivity were receiving antiviral prophylaxis.

HBsAg was negative in $68.6 \%$ of patients $(\mathrm{n}=$ 35 ), although Anti-HBc IgG was positive (occult hepatitis). Anti-HCV was positive in $25.5 \%$ of individuals ( $\mathrm{n}=13)$. Among the patients, 19 were tested for HIV, and the results revealed that none of the patients had the virus.

When the patients were investigated, eight unique diagnoses were made: RA (35.3\%), AS (33.3\%), PsA (13.7\%), Vasculitis (7.8\%), Systemic Lupus Erythematosus $(5.9 \%)$, Behcet Disease $(2 \%)$, and Systemic Sclerosis $(2 \%)$.

Our data indicated that eleven distinct immunosuppressive agents were present in the patients: Etanercept (33.3\%), Infliximab (15.7\%), Rituximab (15.7\%), Adalimumab (9.8\%), Golimumab (5.9\%), Tocilizumab (5.9\%), Abatacept (3.9\%), Cyclophosphamide (3.9\%), Certolizumab (2\%), Ustekinumab (2\%), and Tofacitinib (2\%). Table 1 summarizes the duration of biological treatment, the duration of steroid treatment, and the steroid doses.

Eight patients received Rituximab (RTX) (15.7\%). The average length of RTX use was $39.87 \pm 27.48$ months (range from 6 to 96 months). Antiviral prophylaxis was administered to all eight individuals. In none of the eight patients was reactivation observed.

\section{DISCUSSION}

Hepatitis virus infections are a significant issue for rheumatologists, given the difficulties associated with treatment [12-15]. Numerous studies have demonstrated that methotrexate and biologic treatments, such as infliximab, etanercept, adalimumab, and rituximab, can reactivate HBV in dormant HBV carriers [16-21]. Thus, the ACR recommends screening for HBV and $\mathrm{HCV}$ prior to initiating immunosuppressive medication, whether non-biologic or biologic [12]. Although other studies have demonstrated HBV reactivation in patients receiving immunosuppressive therapy for cancer or transplantation at a rate of $20-50 \%$, our investigation found no evidence of $\mathrm{HBV}$ reactivation in any of our 51 patients $(\mathrm{n}=51)$ [22].

Notably, TNF-a is required for immunological responses as a pro-inflammatory cytokine. Thus, when TNF-a inhibitors are administered, the virus is able to evade the host's immune protection systems against infection [9]. Prior to initiating treatment, all patients with rheumatic illnesses should be tested for HBV, as HBsAg carriers must get antiviral prophylaxis $[6,7$, 11]. Chronic autoimmune illnesses require long-term immunosuppressive medication, but chemotherapy is frequently used for brief periods [23]. It is worth noting that, despite immunosuppressive therapy's benefits, long-term use is likely to compromise host immunological functioning. Lee et al. conducted a review of nine studies that comprised 122 individuals with rheumatic illness who tested positive for HBsAg. $15(12.3 \%)$ of 122 individuals acquired HBVr [6]. Etanercept (33.3\%), Infliximab (15.7\%), Adalimumab (9.8\%), Golimumab (5.9\%), and Certolizumab (5.9\%) were utilized by 34 individuals (2\%). There was no evidence of reactivation in any of the patients.

Although Rituximab is the most hazardous medicine due to its HBVr-related side effects, a study found that due to its longer dose interval, Rituximab therapy was safe in individuals with RD [24]. Another study

Table 1. Period of treatment and steroid dose

\begin{tabular}{lccc}
\hline & $\begin{array}{c}\text { Period of biological } \\
\text { treatment (month) }\end{array}$ & $\begin{array}{c}\text { Period of steroid treatment } \\
\text { (month) }\end{array}$ & Steroid dose (mg) \\
\hline HBsAg positive & $36.89 \pm 19.55$ & $41.89 \pm 110.93$ & $1.71 \pm 2.89$ \\
& $(6-72)$ & $(0-480)$ & $(0-10)$ \\
HBsAg negative Anti- & $48.47 \pm 30.76$ & $54.36 \pm 109.36$ & $3.42 \pm 4.72$ \\
HBc IgG positive & $(4-120)$ & $(0-480)$ & $(0-20)$ \\
Anti-HCV positive & $29.07 \pm 25.22$ & $138.84 \pm 183.17$ & $2.69 \pm 2.78$ \\
& $(3-96)$ & $(0-552)$ & $(0-7.5)$ \\
\hline
\end{tabular}


found that the incidence of $\mathrm{HBVr}$ was $40 \%$ to $100 \%$ in $\mathrm{HBsAg}$ positive RA patients receiving rituximab without or with GC therapy, arguing in favor of antiviral prophylaxis in HBsAg positive RA patients receiving rituximab [25]. The surprising finding in this study was the absence of reactivation among the 51 patients, notably among the eight individuals who received antiviral prophylaxis for a period spanning from 6 to 96 months. This finding implies that appropriate antiviral prophylaxis is critical for the health of patients.

Tocilizumab and Abatacept are likely to have an influence on the patient's immune response to HBV, as mentioned in the literature. However, we should keep in mind that the majority of GC research on $\mathrm{HBVr}$ in patients treated with tocilizumab or abatacept has been hampered by small sample sizes [25]. As a result, additional research with a larger cohort of patients is required.

ISDs (e.g., biologics, steroids, and MTX) are highly likely to reactivate HBV. It is worth noting that assessing the risk of reactivation for each treatment is critical for preventing HBV reactivation [12-23].

In a case-control study including RA patients approved by the US Food and Drug Administration, the odds ratio for HBV reactivation was 2.3 for steroids and much lower for TNF blockers than for steroids or MTX [26].

Fukuda et al. [23] found that MTX had a reduced risk ratio for $\mathrm{HBV}$ reactivation than steroids and biologics. The time period between ISD onset and HBV reactivation varied, and the clinical outcome following reactivation was not always aggressive [23]. Chen et al.'s [24] study discovered that HBVr is prevalent in HBsAg-positive RA patients, even more so when combined immunosuppressive therapies with GC are used. Physicians in particular should exercise caution, as antiviral treatment must be justified in light of the risk of $\mathrm{HBVr}$ infection in rheumatic patients receiving various immunosuppressive regimens [25, 27].

The literature is unanimous in recommending that all patients initiating DMARD medication be screened for $\mathrm{HCV}$ infection using anti-HCV antibodies. If the test results are positive, HCV RNA testing should be performed to validate the finding. Patients who have been infected with $\mathrm{HCV}$ for an extended period of time should be referred to a hepatologist. It's important emphasizing two critical points: I it is critical to understand the severity of the underlying chronic HCV infection before making a therapy option. These patients could be assessed for advanced fibrosis or cirrhosis. (ii) When a hepatologist diagnoses HCV, he or she should determine whether or not to initiate antiviral medication $[8,12,28]$.

\section{Limitations}

Our study has some limitations. A retrospective study, for instance, was described. Second, the sample size for HBV carriers was limited to 19 individuals with RD. This is because hepatitis screening has become more prevalent in recent years. However, multicenter trials with a larger number of patients can provide more trustworthy findings.

\section{CONCLUSION}

In summary, HBV infection is screened for all patients receiving immunosuppressive therapy for rheumatic diseases, and antiviral prophylaxis should be administered if necessary.

\section{Authors' Contribution}

Study Conception: BNC, BY, HED, YP; Study Design: BNC, HED, YP; Supervision: BNC, HED, YP; Funding: N/A; Materials: N/A; Data Collection and/or Processing: ESÖ, ANT; Statistical Analysis and/or Data Interpretation: YP, SE, ANT; Literature Review: HED, ESÖ, SE; Manuscript Preparation: BNC, BY and Critical Review: BNC, BY, HED, YP, SE, ANT, ESÖ.

\section{Conflict of interest}

The authors disclosed no conflict of interest during the preparation or publication of this manuscript.

\section{Financing}

The authors disclosed that they did not receive any grant during conduction or writing of this study.

\section{REFERENCES}

1. Merican I, Guan R, Amarapuka D, Alexander MJ, Chutaputti A, Chien RN, et al. Chronic hepatitis B virus infection in Asian countries. J Gastroenterol Hepatol 2000;15:1356-61.

2. Sung JL. Prevention of hepatitis $B$ and $C$ virus infection for prevention of cirrhosis and hepatocellular carcinoma. J Gastroen- 
terol Hepatol 1997;12:S370-6.

3. Chuang WL, Chang WY, Lu SN, Su WP, Lin ZY, Chen SN, et al. The role of hepatitis $\mathrm{B}$ and $\mathrm{C}$ viruses in hepatocellular carcinoma in a hepatitis B endemic area. a case-control study. Cancer 1992;69:2052-4.

4. European Association for the Study of the Liver. EASL clinical practice guidelines: Management of chronic hepatitis B virus infection. J Hepatol 2012;57:167-85.

5. Wasley A, Alter MJ. Epidemiology of hepatitis C: geographic differences and temporal trends. Semin Liver Dis 2000; 20:1-16. 6. Lee YH, Bae SC, Song GG. Hepatitis B virus reactivation in HBsAg-positive patients with rheumatic diseases undergoing anti-tumor necrosis factor therapy or DMARDs. Int J Rheum Dis 2013;16:527-31.

7. Domm S, Cinatl J, Mrowietz U. The impact of treatment with tumour necrosis factor-alpha antagonists on the course of chronic viral infections: a review of the literature. Br J Dermatol 2008; 159:1217-28.

8. Nathan DM, Angus PW, Gibson PR. Hepatitis B and C virus infections and anti-tumor necrosis factor alpha therapy: guidelines for clinical approach. J Gastroenterol Hepatol 2006;21:1366-71.

9. Vassilopoulos D, Calabrese LH. Viral hepatitis: review of arthritic complications and therapy for arthritis in the presence of active HBV/HCV. Curr Rheumatol Rep 2013;15:319.

10. Perrillo RP, Gish R, Falck-Ytter YT. American Gastroenterological Association Institute technical review on prevention and treatment of hepatitis B virus reactivation during immunosuppressive drug therapy. Gastroenterology 2015;148:221-44 e3.

11. Reddy KR, Beavers KL, Hammond SP, Lim JK, Falck-Ytter YT, American Gastroenterological Association Institute. American Gastroenterological Association Institute guideline on the prevention and treatment of hepatitis B virus reactivation during immunosuppressive drug therapy. Gastroenterology 2015;148:215-9.

12. Saag KG, Teng GG, Patkar NM, Anuntiyo J, Finney C, Curtis JR, et al. American College of Rheumatology 2008 recommendations for the use of nonbiologic and biologic disease-modifying antirheumatic drugs in rheumatoid arthritis. Arthritis Rheum 2008;59:762-84.

13. Calabrese LH, Zein NN, Vassilopoulos D. Hepatitis B virus reactivation with immunosuppressive therapy in rheumatic diseases: assessment and preventive strategies. Ann Rheum Dis 2006;65:983-9.

14. Roux CH, Brocq O, Breuil V, Albert C, Euller-Ziegler L. Safety of anti-TNF- $\alpha$ theraphy in rheumatoid arthritis and spondyloarthropathies with concurrent B or C chronic hepatitis. Rheumatology 2006;45:1294-7.

15. Pyrpasopoulou A, Douma S, Vassiliadis T, Chatzimichailidou S, Triantafyllou A, Aslanidis S. Reactivation of chronic hepatitis $B$ virus infection following rituximab administration for rheumatoid arthritis. Rheumatol Int 2011;31:403-4.

16. Laohapand C, Arromdee E, Tanwandee T. Long-term use of methotrexate does not result in hepatitis B reactivation in rheumatologic patients. Hepatol Int 2015;9:202-8.

17. Wendling D, Auge B, Bettinger D, Lohse A, Le Huede G, Bresson-Hadni S, et al. Reactivation of a latent precore mutant hepatitis B virus related chronic hepatitis during infliximab treatment for severe spondyloarthropathy. Ann Rheum Dis 2005;64:788-9.

18. Kuroda T, Wada Y, Kobayashi D, Sato H, Murakami S, Nakano M, et al. Effect of etanercept and entecavir in a patient with rheumatoid arthritis who is a hepatitis B carrier: a review of the literature. Rheumatol Int 2012;32:1059-63.

19. Burmester GR, Landewé R, Genovese MC, Friedman AW, Pfeifer ND, Varothai NA, et al. Adalimumab long-term safety: infections, vaccination response and pregnancy outcomes in patients with rheumatoid arthritis. Ann Rheum Dis 2017;76:414-7. 20. Varisco V, Viganò M, Batticciotto A, Lampertico P, Marchesoni A, Gibertini P, et al. Low risk of hepatitis B virus reactivation in HBsAg-negative/Anti-HBc-positive carriers receiving rituximab for rheumatoid arthritis: a retrospective multicenter Italian study. J Rheumatol 2016;43:869-74.

21. Papalopoulos I, Fanouriakis A, Kougkas N, Flouri I, Sourvinos G, Bertsias G, et al. Liver safety of non-tumour necrosis factor inhibitors in rheumatic patients with past hepatitis B virus infection: an observational, controlled, long-term study. Clin Exp Rheumatol 2018;36:102-9.

22. Perez-Alvarez R, Diaz-Lagares C, Garcia-Hernandez F, Lopez-Roses L, Brito-Zeron, Perez-de-Lis M, et al.; BIOGEAS Study Group. Hepatitis B virus (HBV) reactivation in patients receiving tumor necrosis factor (TNF)-targeted therapy: analysis of 257 cases. Medicine 2011;90:359-71.

23. Fukuda W, Hanyu T, Katayama M, Mizuki S, Okada A, Miyata $\mathrm{M}$, et al. Incidence of hepatitis $\mathrm{B}$ virus reactivation in patients with resolved infection on immunosuppressive therapy for rheumatic disease: a multicentre, prospective, observational study in Japan. Ann Rheum Dis 2017;76:1051-6.

24. Mitroulis I, Hatzara C, Kandili A, Hadziyannis E, Vassilopoulos D. Long-term safety of rituximab in patients with rheumatic diseases and chronic or resolved hepatitis B virus infection. Ann Rheum Dis 2013;72:308-10.

25. Chen MH, Chen MH, Liu CY, Tsai CY, Huang DF, Lin HY, et al. Hepatitis $\mathrm{B}$ virus reactivation in rheumatoid arthritis patients undergoing biologics treatment. J Infect Dis 2017;215:566-73.

26. Oshima Y, Tsukamoto H, Tojo A. Association of hepatitis B with antirheumatic drugs: a case-control study. Mod Rheumatol 2013;23:694-704.

27. Karadağ Ö, Kaşifoğlu T, Özer B, Kaymakoğlu S, Kuş Y, İnanç $\mathrm{M}$, et al. Viral hepatitis screening guideline before biological drug use in rheumatic patients. Eur J Rheumatol 2016;3:2528.

28. Vassilopoulos D, Calabrese LH. Management of rheumatic disease with comorbid HBV or HCV infection. Nat Rev Rheumatol 2012;8:348-57. 


\begin{tabular}{|c|c|c|c|c|c|c|c|c|c|c|c|c|c|c|}
\hline Z & $\frac{0}{0}$ & 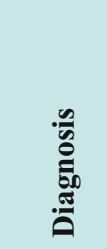 & & & 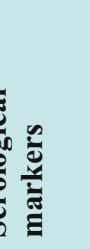 & & 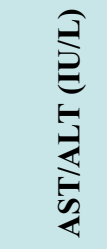 & 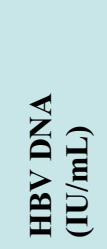 & 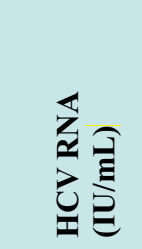 & $\begin{array}{l}\stackrel{0}{0} \\
\frac{0}{0} \\
\stackrel{0}{0} \\
\frac{0}{0}\end{array}$ & 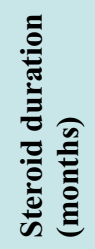 & ڤ & 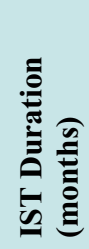 & 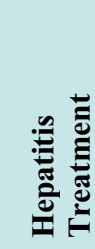 \\
\hline & & & $\begin{array}{l}\sum_{0}^{00} \\
0 \\
0\end{array}$ & 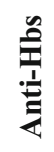 & 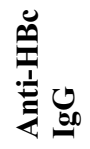 & 党 & & & & & & & & \\
\hline 1 & $28 / \mathrm{M}$ & PsA & - & - & + & - & $17 / 25$ & ND & & 5 & 48 & $\mathrm{ADA}$ & 50 & - \\
\hline 2 & 49/M & AS & + & - & + & - & $14 / 8$ & 112 & & - & - & INF & 6 & TNV \\
\hline 3 & $53 / \mathrm{M}$ & GPA & - & - & + & - & $16 / 17$ & NEG & & 5 & 48 & RTX & 48 & - \\
\hline 4 & $37 / \mathrm{F}$ & AS & - & - & + & - & $39 / 97$ & NEG & & - & - & ETA & 42 & LAM \\
\hline 5 & $48 / \mathrm{F}$ & SLE & - & - & ND & + & $19 / 23$ & & 504.544 & 5 & 552 & RTX & 36 & - \\
\hline 6 & $66 / \mathrm{F}$ & AS & - & - & - & + & $22 / 21$ & & 35.064 & - & - & ETA & 19 & - \\
\hline 7 & $36 / \mathrm{F}$ & PsA & - & - & + & - & $14 / 11$ & NEG & & - & - & ETA & 21 & ENT \\
\hline 8 & $59 / \mathrm{M}$ & PAN & + & - & + & - & $30 / 48$ & NEG & & 5 & 480 & RTX & 45 & LAM \\
\hline 9 & $66 / \mathrm{F}$ & RA & - & - & + & - & $18 / 9$ & NEG & & 5 & 480 & $\mathrm{ABA}$ & 35 & - \\
\hline 10 & $25 / \mathrm{M}$ & AS & + & - & + & - & $22 / 26$ & NEG & & - & 0 & GOL & 39 & TNV \\
\hline 11 & $20 / \mathrm{F}$ & SLE & - & + & - & + & $24 / 18$ & & NEG & 5 & 72 & RTX & 6 & - \\
\hline 12 & $36 / \mathrm{M}$ & AS & - & - & + & - & $27 / 46$ & NEG & & - & 0 & $\mathrm{ADA}$ & 25 & - \\
\hline 13 & $46 / \mathrm{F}$ & RA & + & - & + & - & $19 / 9$ & NEG & & - & 0 & ETA & 48 & TNV \\
\hline 14 & $57 / \mathrm{M}$ & EGPA & - & - & + & - & $14 / 7$ & ND & & 5 & 32 & RTX & 31 & - \\
\hline 15 & $45 / \mathrm{M}$ & PsA & + & - & - & - & $19 / 27$ & NEG & & - & 0 & $\begin{array}{c}\text { UST } \\
\text { E }\end{array}$ & 24 & LAM \\
\hline 16 & $31 / \mathrm{M}$ & SLE & - & - & - & + & $28 / 42$ & & NEG & 7.5 & 60 & $\mathrm{CYC}$ & 4 & - \\
\hline 17 & $29 / \mathrm{F}$ & PsA & - & - & - & + & $11 / 7$ & & NEG & 5 & 48 & ETA & 36 & - \\
\hline 18 & $69 / \mathrm{F}$ & RA & + & - & + & - & $19 / 20$ & 418 & & 5 & 101 & TOCI & 37 & LAM \\
\hline 19 & $56 / \mathrm{F}$ & RA & + & - & ND & - & $22 / 30$ & 48.1 & & - & 0 & ETA & 13 & TNV \\
\hline 20 & $63 / \mathrm{F}$ & PsA & + & - & + & - & $19 / 14$ & NEG & & - & 0 & TOCI & 72 & LAM \\
\hline 21 & $65 / \mathrm{F}$ & RA & + & - & ND & ND & $28 / 24$ & NEG & & 2.5 & 86 & $\mathrm{ABA}$ & 32 & LAM \\
\hline 22 & $63 / \mathrm{F}$ & RA & - & - & + & - & $29 / 27$ & ND & & 5 & 106 & RTX & 96 & - \\
\hline 23 & $53 / \mathrm{F}$ & Ssc & + & + & + & - & $17 / 7$ & NEG & & 5 & 66 & $\mathrm{CYC}$ & 9 & LAM \\
\hline 24 & $65 / \mathrm{F}$ & RA & - & + & + & + & $53 / 65$ & & 1.239 .342 & 5 & 384 & ETA & 3 & $\begin{array}{c}\text { IFN } \\
+ \\
\text { RBV }\end{array}$ \\
\hline 25 & $66 / \mathrm{F}$ & PsA & - & - & + & - & $16 / 2$ & NEG & & 5 & 84 & ADA & 60 & - \\
\hline 26 & $52 / \mathrm{M}$ & AS & + & - & + & - & $18 / 9$ & 30 & & - & 0 & ETA & 60 & TNV \\
\hline 27 & $55 / \mathrm{F}$ & RA & - & - & - & + & $16 / 12$ & & NEG & - & 240 & ETA & 36 & - \\
\hline 28 & $36 / \mathrm{F}$ & AS & - & - & + & - & $14 / 15$ & NEG & & - & 0 & ADA & 39 & - \\
\hline 29 & $67 / \mathrm{M}$ & AS & - & - & + & - & $21 / 21$ & ND & & - & 0 & INF & 85 & - \\
\hline 30 & $45 / \mathrm{M}$ & $\mathrm{BD}$ & - & - & - & + & $41 / 102$ & & NEG & 15 & 52 & INF & 32 & - \\
\hline
\end{tabular}




\begin{tabular}{|c|c|c|c|c|c|c|c|c|c|c|c|c|c|c|}
\hline$\stackrel{0}{Z}$ & 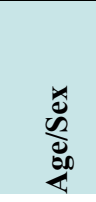 & 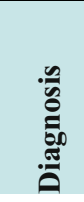 & & & 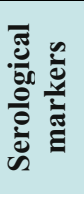 & & 告今 & 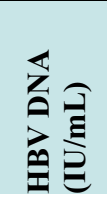 & 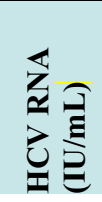 & 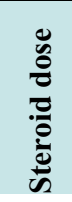 & 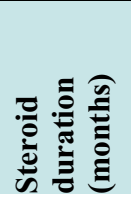 & ڤి & 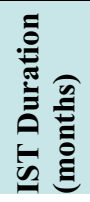 & 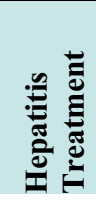 \\
\hline & & & $\begin{array}{l}\sum_{0}^{\infty} \\
0 \\
0\end{array}$ & 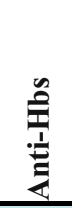 & 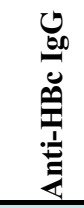 & 总 & & & & & & & & \\
\hline 31 & $66 / \mathrm{M}$ & $\mathrm{RA}$ & - & - & + & - & $23 / 21$ & NEG & & 5 & 96 & GOL & 27 & - \\
\hline 32 & $54 / \mathrm{F}$ & PsA & - & - & + & - & $27 / 17$ & ND & & 5 & 88 & CERTO & 34 & - \\
\hline 33 & $66 / F$ & RA & - & - & + & - & $19 / 10$ & NEG & & 5 & 168 & TOFA & 33 & - \\
\hline 34 & $62 / \mathrm{F}$ & $\mathrm{RA}$ & - & + & - & + & $18 / 15$ & & NEG & - & 0 & TOCI & 42 & - \\
\hline 35 & $27 / \mathrm{M}$ & AS & - & - & + & - & $17 / 43$ & NEG & & - & 0 & INF & 48 & - \\
\hline 36 & $63 / F$ & AS & + & - & + & - & $26 / 21$ & NEG & & - & 0 & GOL & 50 & LAM \\
\hline 37 & $47 / \mathrm{M}$ & AS & + & - & + & - & $15 / 10$ & 18171 & & - & 0 & ETA & 34 & TNV \\
\hline 38 & $49 / \mathrm{M}$ & AS & + & - & + & - & $20 / 20$ & 238 & & - & 0 & ETA & 48 & TNV \\
\hline 39 & $59 / \mathrm{F}$ & AS & - & - & + & - & $35 / 56$ & NEG & & - & 0 & INF & 60 & TNV \\
\hline 40 & $53 / \mathrm{F}$ & AS & + & - & + & - & $19 / 13$ & NEG & & - & 0 & ETA & 52 & LAM \\
\hline 41 & $57 / F$ & $\mathrm{RA}$ & - & - & - & + & $29 / 42$ & & NEG & 2.5 & 360 & ETA & 8 & - \\
\hline 42 & $38 / \mathrm{M}$ & PsA & + & - & + & - & $20 / 18$ & 114 & & - & 0 & ETA & 12 & TNV \\
\hline 43 & $63 / F$ & PAN & - & - & - & + & $25 / 22$ & & NEG & - & 21 & RTX & 45 & $\begin{array}{l}\text { IFN+ } \\
\text { RBV }\end{array}$ \\
\hline 44 & $63 / \mathrm{F}$ & $\mathrm{RA}$ & - & + & - & + & $26 / 21$ & & NEG & 5 & 2 & ETA & 96 & - \\
\hline 45 & $47 / F$ & RA & - & - & + & - & $12 / 18$ & ND & & 15 & 15 & INF & 4 & - \\
\hline 46 & $29 / \mathrm{M}$ & AS & + & - & + & - & $32 / 35$ & NEG & & 0 & 0 & INF & 48 & LAM \\
\hline 47 & $66 / \mathrm{M}$ & RA & + & - & ND & - & $20 / 16$ & 275 & & 10 & 15 & RTX & 12 & LAM \\
\hline 48 & $48 / \mathrm{M}$ & AS & - & - & + & - & $19 / 12$ & NEG & & - & 0 & INF & 120 & - \\
\hline 49 & $35 / \mathrm{M}$ & AS & - & - & + & - & $14 / 10$ & ND & & - & 0 & ETA & 96 & - \\
\hline 50 & $62 / F$ & $\mathrm{RA}$ & - & ND & ND & + & $16 / 13$ & & NEG & - & 24 & ETA & 15 & - \\
\hline 51 & $56 / F$ & RA & + & - & + & - & $19 / 21$ & 90 & & 5 & 48 & $\mathrm{ADA}$ & 60 & TNV \\
\hline
\end{tabular}

PsA = Psoriatic Arthritis, AS = Ankylosing Spondylitis, GPA = Granulomatous Polyangiitis, SLE = Systemic Lupus Erythematosus, PAN = Polyarteritis nodosa, RA $=$ Rheumatoid Arthritis, EGPA $=$ Eosinophilic granulomatosis with polyangiitis, $\mathrm{SSc}=\mathrm{Systemic}$ Sclerosis, $\mathrm{BD}=$ Behcet Disease, ISD = Immunosuppressive drug, ADA = Adalimumab, INF = Infliximab, RTX = Rituximab, ETA $=$ Etanercept, ABA = Abatacept, $\mathrm{GOL}=$ Golimumab, USTE $=$ Ustekinumab, $\mathrm{CYC}=$ Cyclophosphamide, $\mathrm{TOCI}=$ Tocilizumab $, \mathrm{CERTO}=\mathrm{Certolizumab}, \mathrm{TOFA}=$

Tofacitinib, TNV = Tenofovir, LAM = Lamivudine, ENT $=$ Entecavir, IFN+RBV = Interferon+ribavirin. 